СИНИЦын Игорь Михайлович - ученый секретарь Центра исследования проблем безопасности Российской академии наук (117335, Россия, г. Москва, ул. Гарибальди, 21 б; IM_9380752@таil.ru) КАЧАЛОВ Александр Геннадьевич - аспирант Института права и национальной безопасности Российской академии народного хозяйства и государственной службы при Президенте РФ, советник государственной гражданской службы РФ 3-го класса (119991, Россия, г. Москва, ул. Житная, 16; baranzas@mail.ru)

\title{
К ВОПРОСУ ОБ ИДЕОЛОГИЧЕСКОМ ПОИСКЕ В РОССИИ
}

\begin{abstract}
Аннотация. На основе анализа содержания протестов молодежи в XX в. авторы анализируют возможные пути идеологических поисков в России в XXI в., а также рассматривают вопрос практической реализации 13-й статьи Конституции РФ, представляют предложения о целесообразности разработки и принятия в России Концепции идеологической безопасности.

Ключевые слова: национальная безопасность, идеология, молодежь, деструктивные проявления, протест, Конституция, идеологический кризис
\end{abstract}

Работа выполнена в рамках государственного задания ЦИПБ РАН в 2019 году по вопросам исследования проблем обеспечения национальной безопасности Российской Федерации в современных условиях.

$\Pi$ осле распада СССР в результате отсутствия четких социальных и экономических ориентиров дальнейшего развития (по мнению авторов) образовался определенный идеологический кризис, который в первую очередь оказал негативное влияние на духовное состояние молодежи. Несмотря на значительную работу, проводимую государством в направлении формирования и реализации молодежной политики, в силу определенных факторов (таких, как отсутствие достаточных финансовых и материальных ресурсов, а также специалистов в этой сфере деятельности) в молодежной среде продолжаются деструктивные проявления, что в будущем создает реальные угрозы национальной безопасности. В значительной степени такие проявления поддерживаются и подогреваются внешними силами.

Обсуждение вопросов создания в России на современном этапе «идеологических основ» (идеологического поиска) представляется особенно актуальным из-за видимых попыток дестабилизации государства не просто ввиду наличия внутренних угроз, но и, как отмечалось, ввиду ярко выраженного срежиссированного и постановочного характера, имеющего зарубежное происхождение.

На современном этапе государство столкнулись с проблемой пассивности, а порой и негативного отношения со стороны определенных кругов российского общества к необходимости проведения такой работы. Относиться к идеологии можно как угодно. Но есть один весомый фактор, который ограничивает свободу государства в вопросах поиска и выработки идеологических принципов и базисов в России, хотя, как представляется, не ограничивает общество в решении данного вопроса: в ст. 13 Конституции РФ1 признается идеологическое многообразие; не допускается установления никакой идеологии в качестве государственной или обязательной; признается политическое многообразие, многопартийность; запрещается создание и деятельность общественных объ-

\footnotetext{
${ }^{1}$ Конституция РФ от 12 декабря 1993 г. - Собрание законодательства РФ. 26.01.2009. № 4. Ст. 445.
} 
единений, цели или действия которых направлены на насильственное изменение основ конституционного строя и нарушение целостности Российской Федерации, подрыв безопасности государства, создание вооруженных формирований, разжигание социальной, расовой, национальной и религиозной розни.

Уместно рассмотреть мнение Боголюбова С.А. и Сырых В.M. ${ }^{1}$ по вопросу ст. 13 Конституции РФ.

В указанной статье очерчены принципы политической и духовно-идеологической свободы личности и социальных групп общества. Имеется простор для «идеологического творчества».

Авторы комментария указывают, что идеологическое многообразие выражается в возможности личности и общества:

1) обсуждать, критиковать и предлагать улучшения в экономической, политической, правовой и иных сферах государственного устройства России;

2) использовать средства массовой информации и коммуникации для озвучивания и пропаганды своих идей и взглядов;

3) вести активную агитационно-идеологическую работу по продвижению своих идей: разрабатывать программы, проекты, концепции и прочие документы.

Граждане России вправе придерживаться той или иной идеологии, принимать активные меры по ее практической реализации. Этот выбор должен быть осознанным и добровольным. Государство не должно навязывать гражданам идеологию под страхом административной или уголовной ответственности за отказ от следования ей.

Властные полномочия являются мотивацией для различных социальных групп и политических партий вести борьбу за включение в состав государственных органов своих сторонников, чтобы с их помощью реализовывать свои идеологические концепции.

Идеологическое многообразие в стране гарантируется закрепленным в ч. 3 ст. 13 Конституции принципом многопартийности и политического многообразия.

В комментариях достаточно объективно отражены содержание и сущность статьи. Однако целесообразно отметить, что статья Конституции РФ не накладывает запрет на разработку такого базового идеологического документа, который бы определял векторы идеологического воспитания и формирования мировоззрения молодежи, не только позволял бы влиять на ее сознательное, активное и позитивное участие в развитии страны и управлении государством в качестве самостоятельного актора, но и закладывал будущее ее развития в процессе преобразования современного мира в целях реализации и защиты национальных интересов.

Наибольшую опасность представляет установление одной монополистической идеологии, что и запрещается ч. 2 ст. 13 Конституции РФ. Этот принцип запрещает законодательное закрепление единой идеологии в стране, что ведет к идейно-духовному плюрализму и свободе мнений. Создается равноправие различных идей и взглядов в духовно-идеологической сфере. Выбор той или иной идеологической концепции личностью должен быть свободным, осознанным и самостоятельным [Бархатова 2010].

Государство - это система, которая не может действовать на основании «ничего». Для любого государства необходимо идеологическое обоснование

\footnotetext{
1 Комментарий к 13 статье Конституции РФ Боголюбова С.А. и Сырых В.М. Доступ: http:// az-design.ru/Projects/AZLibrCD/Law/Constn/KRF93/krf013.shtml (проверено 02.03.2015).
} 
деятельности и развития как на государственном уровне, так и на уровне личности, общества, в т.ч. бизнеса.

По нашему мнению, с учетом активизации экономического и идеологического давления со стороны ряда государств Запада в России настало время начать обсуждение вопроса принятия Концепции идеологической безопасности Российской аФедерации.

Принятие такого документа и его изучение и обсуждение, в т.ч. в школах в рамках специальных курсов (возможно, и не обязательных), таких, например, как граждановедение, история, обществознание, литература и иных, должны способствовать воспитанию молодого поколения в духе патриотизма и любви к Родине. Конечно, в Концепцию идеологической безопасности Российской Федерации должны войти идеи нравственности и морали, русского языка как носителя менталитета граждан России, уважения и гордости за историю России, лучшие страницы российской и мировой литературы, отечественного кинематографа, возрожденного документального кино как воспитателя поколений, базисные ценности личности вплоть до эгоцентризма.

Основными вопросами, которые должны стать предметом такого обсуждения, могли бы стать:

- совокупность системных упорядоченных взглядов, выражающих интересы различных социальных классов и других социальных групп, на основе которой осознаются и оцениваются отношения людей и их общностей к социальной действительности в целом и друг к другу, в т.ч. существующие или возможные формы государственного управления и власти;

- вопросы необходимости их преобразования и преодоления существующих разногласий и проблем;

- вопросы определения и оценки собственной значимости в управлении государством и распределения результатов, полученных государством, и др.

Таким образом можно было бы заложить некоторые идеологические базисы достижения целей деятельности государства, в т.ч. и на будущее, где движущей силой такой деятельности, безусловно, является молодежь.

С учетом изложенного можно говорить о наличии понятия «идеологическая безопасность» как составной части национальной безопасности, пронизывающей все стратегические направления ее обеспечения. В статье под этим термином (в узком, обобщенном виде) предлагается понимать состояние защищенности личности и общества от деструктивного идеологического внешнего воздействия.

Необходимо оговориться, что наличие идеологических установок, базисов не означает какого-либо преследования за неследование им.

На современном этапе развития России сложно выделить какие-либо наиболее значимые направления формирования идеологических доктрин, т.к. системная работа в данной области в должной мере не проводилась.

Теоретически способы формирования современной идеологии в РФ можно представить как 1) формирование «сверху»; 2) формирование «снизу».

На протяжении нулевых годов были две попытки внедрения идеологии в России «сверху»: 1) российский консерватизм («Единая Россия»); 2) уверенная демократия (В.Ю. Сурков).

Говорить о применении озвученных выше способов в чистом виде нельзя, т.к. проявление в чистом виде данных способов есть не что иное, как насаждение и предложение населению идеологических воззрений властью, без учета мнения населения; во втором случае - революция.

В основном на практике встречается объединенный вариант этих двух способов, когда власть, основываясь на истории, менталитете, мнении народа, 
изучая и обобщая желания и взгляды ныне живущих граждан страны, пытается выработать и внедрить идеологические принципы в массы.

Внедрение происходит путем качественного обоснования и подачи идей, которые, безусловно, должны быть заложены у граждан данного государства на подсознательном уровне.

В России предпринимались попытки использовать именно смешанный вариант формирования идеологических базисов, который, по мнению автора, является наиболее рациональным и приемлемым для любого государственного образования, т.к. исключает вероятность жесткого насаждения в массы идей либо революционных методов.

Можно выделить способы формирования идеологии путем принятия населением идеологических концепций различных политических партий, но в России данная практика не увенчалась успехом, т.к. идеологические платформы наших политических партий очень слабы, а зачастую их даже нельзя назвать таковыми. Наиболее обоснованной исторически является идеологическая платформа КПРФ, но в связи с потерей своей актуальности в России и мире в основном электоратом данной политической силы являются идеологические выходцы из СССР. Таким образом, идеологическая платформа КПРФ на современном этапе уже не является интересной для большей части молодого поколения.

Какой-либо политической партии, которая бы предложила населению качественный идеологический продукт, в России пока нет.

На заседании клуба «Валдай» в 2013 году1 президент РФ впервые уделил внимание именно вопросам идеологии, что вызвало череду обсуждений, круглых столов по данной проблематике.

В 2019 г. В.Ю. Сурков в статье «Долгое государство Путина» отмечал, что глубинного государства в России нет, оно все на виду, зато есть глубинный народ. Глубинный народ всегда себе на уме, он недосягаем для социологических опросов, агитации, угроз и других способов прямого изучения и воздействия. Своей гигантской супермассой глубинный народ создает непреодолимую силу культурной гравитации, которая соединяет нацию и притягивает (придавливает) к земле (к родной земле) элиту, время от времени пытающуюся космополитически «воспарить». Современная модель русского государства начинается с доверия и на доверии держится. В этом ее коренное отличие от модели западной, культивирующей недоверие и критику [Сурков 2019].

По мнению президента России В.В. Путина, суверенитет, самостоятельность, целостность России безусловны. Это те «красные линии», за которые нельзя никому заходить. При всей разнице наших взглядов дискуссия об идентичности, о национальном будущем невозможна без патриотизма всех ее участников. Патриотизма в самом чистом значении этого слова 2 .

Территориальная целостность, территориальная независимость, государственный суверенитет, идеология, основанная на традиционных ценностях, истории, восприятие позитивного мирового опыта - это фундаментальные идеологические базисы российского общества, основанные на богатом историческом опыте, глубинном менталитете русских.

Россия территориально расположилась между Востоком и Западом, но сумела сохранить свою самобытность, что также должно быть интегрировано в основу новой идеологической концепции, которая на самом деле является естественным состоянием российского общества, привыкшего жить в условиях террито-

\footnotetext{
1 Выступление Президента России В.В. Путина: материалы заседания международного дискуссионного клуба «Валдай». 19.09.2013. Доступ: http://www.kremlin.ru/events/president/news/19243 (проверено 31.08.2019).

2 Там же.
} 
риальной, граничной идеологии, когда извне воспринимается только лучшее и в рамках государства перерабатывается на российский лад.

Консолидирующие ценности нации - это совокупность доминирующих в обществе духовных и материальных ценностей, позволяющая эффективно осуществлять социальную регуляцию на общенациональном уровне. Важнейшей консолидирующей ценностью, безусловно, является патриотизм - любовь к отечеству, готовность защищать его, уважение к историческому прошлому своей страны, гордость за культурные и иные достижения предшествующих поколений, стремление сделать жизнь в России лучше для последующих поколений.

Ко второй консолидирующей ценности развивающегося общества относится труд. Самой высокой оценки в обществе, общими усилиями строящем «Потребное» будущее, заслуживает трудолюбие, профессионализм, честное, порядочное отношение к своим обязанностям, творческое профессиональное самовыражение. Необходимо развивать культ профессионалов во всех сферах жизнедеятельности общества. А на сегодняшний день ценится не хорошая работа, а умение «рубить бабки».

Основой прогрессивного развития всех социальных групп общества является свобода. Свобода понимается как возможность осознанного независимого выбора при принятии решений в рамках правового поля. В России за свободу часто принимают вседозволенность, а основная неформальная норма - это первобытное право сильного.

Новое смысловое наполнение и значение в условиях глобализации приобретают общецивилизационные ценности, не связанные с определенным историческим этапом или национальными традициями конкретного общества, но принятые им как ценностные ориентиры. Безусловно, сама жизнь и необходимость ее сохранения и развития является основополагающей ценностью. К общечеловеческим ценностям относят нравственные ценности (счастье, смысл жизни, добро, совесть, долг, ответственность, честь, достоинство и др.), эстетические (прекрасное), политические (мир, демократия), правовые (закон и правовой порядок), религиозные (вера), научные (истина). Следует отметить, что интерпретация вышеназванных ценностей имеет национальный оттенок.

Идеология - это совокупность руководящих идей об организации и развитии общества, способная к реализации в этом обществе, т.е. способная найти практический отклик у широких слоев населения. Национальная идея выражает миссию нации в настоящем и будущем, общую консолидирующую цель и связь с эволюционным развитием мирового сообщества. Общенациональная идеология становится фундаментом гражданского единства, определяет вектор развития нации и связанные с ним базовые консолидирующие ценности и приоритеты, объединяет граждан для решения наиболее значимых проблем общества.

Национальная идея определяет стратегические цели выживания, процветания и развития нации, объединяет людей независимо от их личных убеждений и идеологий различных социальных и политических групп. К определяющим формирование национальной идеи факторам относятся:

- историческая преемственность, межпоколенческие связи;

- будущий образ России;

- стремление к благосостоянию;

- интегрированность в мировой эволюционный процесс;

- их разработка и обоснование интеллектуальной элитой нации.

Национальная идея - это центральный и основополагающий вектор движения развития человека, общества и государства. Инструментом, обеспечива- 
ющим реализацию национальной идеи, является государственная идеология. Бесспорным является тезис, что самыми эффективными являются проекты, в которых есть уникальная идея. Бесспорно, что в России с ее более чем тысячелетней историей сложился основательный идейный плацдарм. Бесспорно, что глобализационные тренды ставят отдельно взятые государства перед фактами разрушительных тенденций. В подобных условиях противостоять идеологической экспансии оружием не получится - необходима сильная «идеологическая вакцинация» населения, что не означает применение политики «железного занавеса». Необходимы четкие и отлаженные методы, механизмы, способы реализации тех национальных особенностей России, которые в процессе тысячелетней истории интегрировались в менталитет и сознание русского народа - народа, который объединен единством территории, общей историей и будущим.

Только сплоченные идеологическими скрепами государства могут оставаться в авангарде человеческой истории.

Важность правильных идеологических установок молодежи в достаточной мере иллюстрируют молодежные бунты XX в. Анализ исторического опыта имеет важнейшее значение в процессе разработки положений идеологической безопасности и воспитания молодого поколения.

В декабре 2017 г. Оксфордский словарь признал словом года youthquake, что дословно означает «молодежное потрясение», или «молодежный бунт», содержанием и результатом которого являются значимые культурные, политические или социальные перемены, вызванные действиями или влиянием молодежи ${ }^{1}$.

Youthquake уже ранее упоминалось в отмеченном словаре, но в 2017 г. оно пережило бум употребления: оно упоминалось на $401 \%$ чаще, чем прежде.

Молодежный бунт - это действия, направленные на реализацию процесса революционных изменений политического, социального и культурного характера, осуществляемого при активном участии молодежи.

Данный термин был введен еще в 1960-х гг. и представлял собой процесс «Переворота» в моде и музыке, инициаторами которого были молодые британцы. В настоящее время этот термин приобретает иное содержание - политическое и социальное.

Процесс активизации участия молодежи в политической и социальной жизни происходил под влиянием распространившегося в молодежной среде сомнения в адекватности институтов капитализма и либеральной демократии. В 1968 г. в Западной Европе и Северной Америке, Египте, Турции, Мексике, Бразилии, Югославии, Польше возникли массовые студенческие беспорядки.

Лозунгами молодежи стали: «Вся власть воображению!», «Беги, товарищ, старый мир у тебя за спиной», «Запрещено запрещать!», «Революция невероятна, ибо она истинна!»

Угнетение личности, загипнотизированность средствами массовой информации, культ потребления приводили молодежь к осознанию, что необходимо свержение действующей культуры, строительство принципиально новых межличностных отношений, создание «новой личности».

В 1968 г. Европу охватили молодежные бунты. Пиком активности стал май 1968 г. во Франции, когда страну потрясли массовые студенческие беспорядки. Франция «горела», бастовала.

Необходимо отметить, что Франция выступает одним из авангардов протестного движения: так, в 2018 г. во Франции зародилось спонтанное протестное движение без выраженного лидера, получившее название движения желтых жилетов (фр. - mouvement des Gilets jaunes).

\footnotetext{
${ }^{1}$ https://knife.media/youthquake/ (проверено 31.08.2019).
} 
Движение получило свое название из-за светоотражающих желтых жилетов, используемых участниками митингов с целью идентификации принадлежащих к этому движению. Изначально причиной данных протестов послужило повышение цен на топливо (вследствие повышения цены на нефтепродукты), затем требования участников расширились до отставки президента Франции Э. Макрона. Движение быстро набирает обороты, приобретая политическую окраску. Под символом желтых жилетов начали происходить акции протеста в других странах ${ }^{1}$ (Великобритания, Бельгия, Нидерланды, Канада, Израиль, Австралия, Россия и др.).

В 1960-х гг. американская молодежь остро осознала проблему обретения своего места в обществе, результатом чего стало обострение социальных и политических конфликтов в США. Происходил массовый подъем демократических движений, основу которых составляли молодежь и студенческие объединения.

В этот же период среди афроамериканцев в США зарождается и получает распространение идеология черного национализма. Выдвигаются призывы к самостоятельному контролю своего движения, политических, социальных и экономических институтов, без контроля белых.

В 70-х гг. XX в. движение контркультуры распалось на различные группы: хиппи, панки, рокеры и др.

Битники, хиппи представляли собой аполитичный протест: вызывающая одежда, нестандартное поведение, стремление уйти от навязываемых обществом ценностей, проповедь всеобщей любви и свободы от нравственных оков. Так, символом выражения любви у хиппи стал цветок, олицетворяющий цветущую марихуану.

Отличия были незначительными: одежда, музыкальные пристрастия, отношение к наркотикам и алкоголю.

В 80-х гг. XX в. контркультура проникла в Россию. Появились люберы, скинхеды и др. Девяностые годы привели к политизации этих движений, молодежь стала участвовать в митингах и демонстрациях, стояла живым кольцом у Белого дома в 1991 г.

Интересным является факт, что в настоящее время в США получают все большее распространение радикальные коммунистические идеи. Fox News пишет, что подобные идеи распространяются среди американской молодежи, главной из них является идея о революции и разрыве с традиционными ценностями. Отмечается, что идеи К. Маркса теперь продвигает не Россия или Китай, а американские студенты и профессора.

В настоящее время «мода на революции» возрастает. Так, в 2019 г. в Армении прошел семинар СатрСатр, организованный американскими фондами, где молодых активистов из России и других республик постсоветского пространства обучали организации протестов в своих городах и странах ${ }^{2}$.

Важно отметить, что современные акции протеста нацелены не только на сбор большого числа людей в определенном месте, посредством чего выражается недовольство властью или социальными проблемами, но и в первую очередь на виртуальную аудиторию, т.к. короткое видео, фото в течение считанных минут могут распространиться пользователями сети Интернет среди миллионов юзеров и вызвать еще большую реакцию в обществе, чем несколько сотен человек, стоящих на площади. Главная задача - сформировать правильный информационный повод и транслировать его на огромную аудиторию с помощью СМИ и

\footnotetext{
1 Движение желтых жилетов. - Википедия. Доступ: https://ru.wikipedia.org/wiki/Движение_желтых_жилетов (проверено 31.08.2019).

2 Мода на революцию: как молодежь учат совершать госперевороты на западные деньги. - $R T$. Доступ: https://russian.rt.com/world/article/601738-moda-na-revolyuciyu (проверено 31.08.2019).
} 
социальных сетей. Митинг уже не так важен как событие в реальном мире - он куда важнее как сообщение, которое адресуется через виртуальную реальность.

Роль социальных сетей в акциях протеста уже не сводится к простой возможности привлечь как можно больше людей к митингам, а также быстро координировать их действия, сейчас акция протеста - это в первую очередь определенное сообщение для людей, которые являются его наблюдателями не в реальном, а в виртуальном пространстве.

Грамотный подход к историческому опыту молодежных движений, трактовке и пониманию ст. 13 Конституции РФ, понимание важности правильных идеологических установок современной молодежи ведет к осознанию необходимости разработки и внедрения Концепции идеологической безопасности Российской Федерации. Принятие данной концепции не будет противоречить конституционным принципам, т.к. она выступит концепцией норм и принципов, определяющих правильное воспитание молодого поколения, культивирование в нем правильных идеологических установок, набором способов и методов правильного воспитания, энциклопедией идеологических ценностей, сохраняющих ценности уважения свободы человека и гражданина, частной собственности, морали и нравственности, толерантности и взаимного уважения, энциклопедией цифровой гигиены и этикета виртуальных взаимоотношений и общения.

Идеологические установки современной молодежи, идеологические поиски современного общества - это естественным образом сформировавшиеся запросы цивилизации, которая устала от бесконечного материального насыщения и испытывает глубоко духовные потребности. К сожалению, необходимость в удовлетворении таких потребностей осознается государственными структурами в недостаточной мере, что ведет к поиску социумом способов их удовлетворения посредством деструктивных методов и средств.

\section{Список литературы}

Бархатова Е.Ю. 2010. Комментарий к Конституции Российской Федерации. М.: Проспект. 377 с.

Сурков В.Ю. 2019. Долгое государство Путина. Доступ: http://www.ng.ru/ ideas/2019-02-11/5_7503_surkov.html (проверено 31.08.2019).

SINITSYN Igor Mikhailovich, Scientific Secretary of the Center for Security Studies, Russian Academy of Sciences (21b Garibaldi St, Moscow, Russia, 117335; IM_9380752@mail.ru)

KACHALOV Aleksandr Gennad'evich, postgraduate student at the Institute of Law and National Security, Russian Presidential Academy of National Economy and Public Administration (RANEPA); Counselor of the State Civil Service of the Russian Federation, $3^{\text {rd }}$ class (16 Zhitnaya St, Moscow, 119991, Russia; baranzas@mail.ru)

\section{ON THE ISSUE OF IDEOLOGICAL SEARCH IN RUSSIA}

Abstract. Based on the analysis of the content of youth protests in the $20^{\text {th }}$ century, the article presents the possible ways of ideological searches in Russia in the $21^{\text {st }}$ century. The authors consider the practical implementation of article 13 of the Constitution of the Russian Federation, and give proposals on the feasibility of developing and adopting the concept of ideological security in Russia.

Keywords: national security, ideology, youth, destructive manifestations, protest, Constitution, ideological crisis 